\title{
Remote Sensing of Night Lights-Beyond DMSP
}

\author{
Noam Levin ${ }^{1, *} \mathbb{D}$, Christopher C.M. Kyba ${ }^{2,3} \mathbb{D}$ and Qingling Zhang ${ }^{4,5}$ \\ 1 Department of Geography, The Hebrew University of Jerusalem, Mount Scopus, Jerusalem 91905, Israel \\ 2 German Research Center for Geosciences (GFZ), Telegrafenberg, 14473 Potsdam, Germany; \\ kyba@gfz-potsdam.de \\ 3 Leibniz-Institute of Freshwater Ecology and Inland Fisheries (IGB), Müggelseedamm 310, \\ 12587 Berlin, Germany \\ 4 Shenzhen Institutes of Advanced Technology, Chinese Academy of Sciences, Shenzhen 518055, China; \\ zhangqling@mail.sysu.edu.cn \\ 5 School of Aeronautics and Astronautics, Sun Yat-Sen University, Guangzhou 510275, China \\ * Correspondence: noamlevin@mail.huji.ac.il; Tel.: +972-2-588-1078
}

Received: 8 June 2019; Accepted: 17 June 2019; Published: 21 June 2019

\begin{abstract}
Remote sensing of night lights differs from other sources of remote sensing in its ability to directly observe human activity from space as well as in informing us on a new type of anthropogenic threat, that of light pollution. This special issue focuses on studies which used newer sensors than the Defense Meteorological Satellite Program - Operational Line-Scan System (DMSP/OLS). Most of the analyses focused on data from the Visible Infrared Imaging Radiometer Suite (VIIRS) nighttime sensor (also called the Day/Night Band, or VIIRS/DNB in short), for which the first instrument in the series was launched in 2011. In this editorial, we provide an overview of the 12 papers published in this special issue, and offer suggestions for future research directions in this field, both with respect to the remote sensing platforms and algorithms, and with respect to the development of new applications.
\end{abstract}

Keywords: night lights; VIIRS/DNB; urban

\section{Background}

Remote sensing of night-time lights offers a unique ability to monitor human activity from space. Since the 1990s, many studies have taken advantage of the Defense Meteorological Program Operational Line-Scan System (DMSP/OLS) sensors, to monitor artificial lights from space and to quantify the relationships between human activity and socio-economic variables or night-time brightness, as well as to quantify the extent and impact of light pollution. Traditionally, most research was done utilizing the DMSP/OLS, which for many years provided the only source for observing night-time brightness, as reviewed in various papers [1-6].

In the last decade, new avenues have opened to advance the study of remote sensing of night lights, with the availability of new sensors offering better spatial, temporal and radiometric resolution than DMSP/OLS (see e.g., [7]). Previous special issues devoted to remote sensing of night lights were published in the journal Remote Sensing in 2014 (Remote Sensing with Nighttime Lights, edited by Chris Elvidge, who is widely regarded as the founder of the discipline of remote sensing of night lights), and in 2017 (Recent Advances in Remote Sensing with Nighttime Lights, edited by Bailang Yu, Yuyu Zhou, Chunyang He and Xiaofeng Li, reflecting the immense use of night light imagery by Chinese scholars), as well as in the journal International Journal of Remote Sensing in 2017 (see cover paper of [8]). Both of these special issues covered studies using both DMSP/OLS and other sensors.

Within this special issue, we aimed to highlight novel research on remote sensing of night lights going beyond the DMSP/OLS. We especially aimed for studies examining the potential of new sensors (such as Visible Infrared Imaging Radiometer Suite (VIIRS/DNB), and other emerging new sensors) to 
quantify night-time brightness at fine spatial and temporal resolutions, the generation of products from the VIIRS/DNB sensor (e.g., stable lights, gas flares, wildfires, etc.), the correction of atmospheric and lunar effects on the measured signal, and the correspondence between ground observations of artificial lights and light pollution and space borne measurements of night time brightness.

\section{Papers in the Special Issue}

The papers published in this special issue illustrate the breadth of research conducted in this field, concerning both different sources of night-time lights (fires, fisheries and urban areas), the factors explaining night-time brightness (such as economic variables and land use), and the use of time series of night-time lights as an indicator for the impact of natural and human induced disasters.

While most of the papers focused on applications of night lights, one paper discussed the stability of the datasets themselves. Coesfeld et al. [9] examined how the radiance of individual pixels varied from month-to-month in the monthly composite images of VIIRS/DNB data produced by the Earth Observation Group (EOG) of the National Oceanic and Atmospheric Administration (NOAA). They selected multiple sites in USA and Canada that included 11 different types of land use or land cover, and compared the monthly values to the median for each location. They found that the radiance of most pixels was characterized by a normal distribution, with a typical standard deviation of $15-20 \%$ of the mean, although some light sources such as greenhouses and flares are much more variable. Coesfeld et al. [9] also reported that the temporal variation from one month to the next was spatially correlated, even over distances of several hundred kilometers.

The Earth Observation Group has been studying light from combustion sources for decades (e.g., [10]). In Elvidge et al. [11], they continue their work in this area, showing that the incorporation of VIIRS/DNB data to data from the VIIRS near infrared and shortwave infrared bands could allow the detection of far more fires than can be observed via longer wavelength VIIRS infrared observations alone. This work arose from their observations while attempting to produce maps of electric lights. They noticed that there were large numbers of biomass burning events which were visible in DNB, but were not flagged by the "VIIRS nightfire" product. The authors therefore examined an area of central India known to have a great deal of biomass burning events related to agriculture, and found that the inclusion of DNB allowed the detection of 15 times more fires than were detectable with the longer wavelength VIIRS infrared bands alone. This factor cannot be expected to apply globally, however, as most regions with biomass burning do not have such a large number of small scale fires. Elvidge et al. [11] note that if DNB is to be used to detect combustion sources, it is important to restrict the analysis to regions that are outside of areas in which electric light is present.

While fires represent an ephemeral source of light at night on land, fishing boats that use lights to attract their catch, represent an ephemeral source of light at night in some of the seas and oceans of the world [12,13]. With the launch of VIIRS/DNB, Elvidge et al. [14] developed an algorithm to identify the locations of boats based on lights with low temporal latency, which is available online at https://eogdata.mines.edu/vbd/. Analyzing VIIRS Boat Detection (VBD) data for the Philippines between the years 2012 and 2016, Geronimo et al. [15] have demonstrated that VBD data can be effectively used to identify and model core fishing areas, which were mostly explained by the environmental predictors of bathymetry and chlorophyll.

Fisheries provide one of many examples of how economic activity can be identified by night-time lights. Indeed, night-time data has already been used to estimate GDP and other economic indicators at the country level, for example using DMSP/OLS data [16]. Given the better spatial resolution of VIIRS/DNB, it is superior to DMSP/OLS in its ability to estimate GDP and electric power consumption [17]. In their paper in this special issue, Wu et al. [18] have used VIIRS/DNB data to analyze regional inequality in economic activity in China, both within provinces and between provinces, applying the Theil index. In their analysis Wu et al. [18] found economic inequality to be lower in the coastal provinces of China than in China's western provinces. Given that Goal \#10 of the United Nations sustainable development goals is to reduce inequality between and within countries, 
night-time lights could provide some indication as to what degree countries are progressing towards achievement of this goal.

On the global scale, the total lit area of Earth has grown during the period of operation of VIIRS/DNB, with the proportional rate of increase largest in developing countries [19]. Nevertheless, there are some notable cases in which lighting decreases. Among these are humanitarian disasters, caused either by natural phenomena or through war [20], as well as economic and sometimes population decline. In their paper in this special issue, Li et al. [21] examined how VIIRS/DNB lighting trends in EOG's monthly composites related to the activities of the self-proclaimed "Islamic State of Iraq and Syria" (ISIS) and the Iraqi Security Forces (ISF). They found that when ISIS took control of a region, the light emission dropped dramatically: up to $88 \%$ in the case of Ninawa province. The cities in Northern Iraq were also examined. In the case of Tikrit, light emissions were completely extinguished for nearly a year during 2014-2015. Many areas became lit again once the region was retaken by the ISF.

In contrast to wars, which impact light emissions over long time periods, natural disasters can have shorter impacts. In their paper in this special issue, Zhao et al. [22] examined how earthquakes, floods, and storms affect night light emissions, using nightly VIIRS/DNB, rather than the monthly composites from EOG. Specifically, they created composite DNB images based on the nightly data in the month prior to the event, and compared them to another composite image made using the data for the 10 days after the event. Cloudy pixels were not included in the composite, and moonlight was subtracted using a lunar illuminance model. The authors found that an area of $900 \mathrm{~km}^{2}$ increased in brightness after the Central Italy Earthquake in 2016, and attributed this to increased use of rescue lights. We personally have doubts about this interpretation, and suspect it is perhaps more likely to be due to errors in the moonlight subtraction or variation due to the viewing geometry [9]. In the case of Hurricane Maria in Puerto Rico, Zhao et al. [22] found that the decrease in light was far larger than the extent of building damage, and attribute the light decrease to damage to the energy infrastructure, rather than buildings. There was an extremely strong correlation $\left(R^{2}=0.96\right)$ between the proportion of customers reported as having no power and the percentage decrease in light emission compared to the baseline before the hurricane.

Human activities and infrastructures are noticeably concentrated in urban areas, thus mapping urban extents is almost naturally the first wave of applications researchers implemented with nighttime light remote sensing data. Traditionally, due to DMSP/OLS' panchromatic nature, thresholding was the most popular and practical way to extract urban information from nighttime lights. However, optimal thresholds vary across space, and a scheme of dynamic thresholds is required for large-scale and temporal dynamic urban extent mapping. The difficulty of determining optimal thresholds remains challenging to applications of this method even with VIIRS/DNB data, which also contains one single panchromatic band. In their paper in this issue, $\mathrm{Li}$ and Chen [23] aimed to address this problem. They proposed a Genetic Algorithm-based urban cluster automatic threshold (GA-UCAT) method by combining VIIRS/DNB, MODIS NDVI, and Normalized Difference Built-up Index (NDBI) data to distinguish urban areas from dark rural background in VIIRS/DNB images. The key point of this proposed method is to design an appropriate fitness function of GA by means of integrating between-class variance and inter-class variance with all these three data sources to determine optimal thresholds.

Ma and Li [24] proposed an object similarity-based thresholding method using VIIRS DNB data to map urban areas. The threshold for a target potential urban object was determined by comparing it with all reference urban objects with known optimal thresholds derived from Landsat data. The authors claimed that the proposed method performed better than the cluster-based logistic regression method.

Ma et al. [25] proposed a watershed-based partitioning approach, by combining a second order exponential decay model for the spatial delineation of human settlements with VIIRS-derived nighttime light images. Their method is based on local lighting hotspots, and identifies adjacent units like a topographic map. Satellite-derived building density data and social media-based human activity information are jointly used to further identify partitioned sub-regions into different types of lighting 
areas. In this way, urban areas are not only delineated but also classified into five different types in terms of the degree of human activity.

To curb the fast yet disorderly urbanization trends, especially in developing countries, urban boundaries are treated as effective administrative tools to confine urban development within areas encompassed by identified urban boundaries. Xue et al. [26] found that by combining VIIRS/DNB nighttime light data with daytime Landsat-8 multispectral data, they can effectively detect urban boundaries at a $30 \mathrm{~m}$ spatial resolution, which can otherwise be often time-consuming and ineffective. They first identified a rough urban boundary for an urbanized region of interest by a search mode of the concentric zones model and a variance-based approach. A buffer zone was then constructed to encompass the precise UB that is near the rough UB within a certain distance. Finally, an edge detecting method was adopted to obtain the precise UB with a spatial resolution of $30 \mathrm{~m}$.

Most papers in both this special issue as well as in the scientific literature of remote sensing of night lights use coarse spatial resolutions sensors (such as DMSP/OLS and VIIRS/DNB). The only paper within this special issue taking advantage of the new generation of higher spatial resolution satellites is that of Du et al. [27]. They used the commercial Jilin-1 satellite to examine its potential to model house vacancy rate within the city of Buffalo (New York, USA). Vacant urban lands, where houses are abandoned, are a type of urban decay that signifies an economic decline. While time series of night-time lights have been successfully used in the past to monitor the decrease in economic activity at the regional and national levels (e.g., [6]), this paper [27] is the first to show the value of high spatial resolution night-time imagery for examining urban decline patterns at the neighborhood scale.

The final paper in this special issue addresses urban heat. One of the impacts of the urbanization process, is an increase in energy consumption and, as a consequence, increased release of anthropogenic heat $(\mathrm{AH})$ into the atmosphere. Understanding and quantifying $\mathrm{AH}$ is important for both climate change models and to estimate human thermal comfort and its relationship with the urban heat island phenomenon. Energy consumption has been previously estimated based on night-time lights, and has also been shown to be correlated with the intensity of the night-time urban heat island surface [28]. Within their paper in this special issue, Chen and $\mathrm{Hu}$ [29] showed that anthropogenic heat flux can be spatially modelled and mapped using VIIRS/DNB, taking as their case study the Beijing-Tianjin-Hebei region in China.

\section{Outlook to the Future}

The increase in the availability of night-time sensors, with better spectral, temporal and spatial resolutions, is allowing new applications and research questions to be tackled, as reflected in the dramatic increase in number of papers published on the topic of light pollution in the past 15 years [30]. Here we will layout some of the main directions we anticipate for future research, distinguishing between studies on improving measurements, and studies focusing on developing new applications. With regards to sensor development, there is a vital need to develop operational multispectral night-time sensors (as already recommended by [31]), especially given the revolution of LED lighting [19]. Additionally, there is a clear need for a geostationary sensor, which will enable the monitoring of circadian patterns of night-time brightness, so as to enhance the temporal resolution of night-time observations [32].

With regards to the methodologies of remote sensing of night lights, we identify the following research avenues as some of the important ones to be pursued:

- How to validate spaceborne measurements of artificial light at night (ALAN), using a combination of unmanned aerial vehicles (UAVs) and ground based sensors (see [33]), given the differences in the directions of measurements? (see [34]).

- How to remove atmospheric scattering and seasonal effects from daily and monthly products of satellite images of night lights, so that the measured signal will express the emissions of light? (see [35]). 
- What are the anisotropic properties of ALAN, and how do the viewing angle and the 3D structure of the cities, affect the measurements of light at night?

- How can the spatial resolution of night-time images be refined, either based on models of light scattering, or based on ancillary layers? (see [36]).

- Provide guidelines on the conversion between different units of measurements, used by lighting engineers, astronomers and the remote sensing community.

With regards to new applications of remote sensing of night lights, these include a wide variety of possible avenues, including:

- Quantifying circadian and seasonal patterns in human aggregation and activity (see [37]).

- Understanding the differences between indoor and outdoor exposure to light pollution, which is of high relevance for epidemiological studies.

- Develop near real time warning systems on energy failures, due to human and natural disasters, especially to assist international aid agencies (see [38]).

- Evaluating transitions towards sustainable outdoor lighting (see e.g., [39,40]).

In summary, remote sensing of night lights is now maturing, and we foresee the development of new operational products, from both existing and emerging new sensors.

Author Contributions: Conceptualization, Writing-Original Draft Preparation, Writing—Review \& Editing; N.L., C.K. and Q.Z.

Funding: CCMK acknowledges funding from the Helmholtz Association Initiative and Networking Fund under Grant ERC-RA-0031 and through the European Union's Horizon 2020 research and innovation program ERA-PLANET, Grant Agreement No. 689443, via the GEOEssential project. QL was funded by the National Key Research and Development Plan of China (Grant No. 2017YFB0504204), the '100 Talents Project' of Chinese Academy of Sciences, China (Grant No. Y674141001).

Conflicts of Interest: The authors declare no conflict of interest.

\section{References}

1. Doll, C.N. CIESIN Thematic Guide to Night-Time Light Remote Sensing and Its Applications; Center for International Earth Science Information Network of Columbia University: Palisades, NY, USA, 2008.

2. Elvidge, C.D.; Erwin, E.H.; Baugh, K.E.; Ziskin, D.; Tuttle, B.T.; Ghosh, T.; Sutton, P.C. Overview of DMSP nightime lights and future possibilities. In Proceedings of the 2009 Joint Urban Remote Sensing Event, Shanghai, China, 20-22 May 2009; pp. 1-5.

3. Huang, Q.; Yang, X.; Gao, B.; Yang, Y.; Zhao, Y. Application of DMSP/OLS nighttime light images: A meta-analysis and a systematic literature review. Remote Sens. 2014, 6, 6844-6866. [CrossRef]

4. Zhang, Q.; Levin, N.; Chalkias, C.; Letu, H. Nighttime Light Remote Sensing-Monitoring Human Societies from Outer Space. In Remote Sensing Handbook; Thenkabail, P.S., Ed.; Chapter 11; Taylor and Francis: New York, NY, USA, 2015; Volume 3, pp. 289-310.

5. Li, X.; Zhou, Y. Urban mapping using DMSP/OLS stable night-time light: A review. Int. J. Remote Sens. 2017, 38, 6030-6046. [CrossRef]

6. Bennett, M.M.; Smith, L.C. Advances in using multitemporal night-time lights satellite imagery to detect, estimate, and monitor socioeconomic dynamics. Remote Sens. Environ. 2017, 192, 176-197. [CrossRef]

7. Kyba, C.; Garz, S.; Kuechly, H.; de Miguel, A.; Zamorano, J.; Fischer, J.; Hölker, F. High-resolution imagery of earth at night: New sources, opportunities and challenges. Remote Sens. 2015, 7, 1-23. [CrossRef]

8. Li, X.; Elvidge, C.; Zhou, Y.; Cao, C.; Warner, T. Remote sensing of night-time light. Int. J. Remote Sens. 2017, 38, 5855-5859. [CrossRef]

9. Coesfeld, J.; Anderson, S.; Baugh, K.; Elvidge, C.; Schernthanner, H.; Kyba, C. Variation of individual location radiance in VIIRS DNB monthly composite images. Remote Sens. 2018, 10, 1964. [CrossRef]

10. Elvidge, C.D.; Nelson, I.; Hobson, V.R.; Safran, J.; Baugh, K.E. Detection of fires at night using DMSP-OLS data. In Global and Regional Vegetation Fire Monitoring from Space: Planning a Coordinated International Effort; Ahern, F.J., Goldammer, J.G., Justice, C.O., Eds.; SPB Academic Publishing Bv: The Hague, The Netherlands, 2001; pp. 125-144. 
11. Elvidge, C.D.; Zhizhin, M.; Baugh, K.; Hsu, F.C.; Ghosh, T. Extending nighttime combustion source detection limits with short wavelength VIIRS data. Remote Sens. 2019, 11, 395. [CrossRef]

12. Davies, T.W.; Duffy, J.P.; Bennie, J.; Gaston, K.J. The nature, extent, and ecological implications of marine light pollution. Front. Ecol. Environ. 2014, 12, 347-355. [CrossRef]

13. Zhao, X.; Li, D.; Li, X.; Zhao, L.; Wu, C. Spatial and seasonal patterns of night-time lights in global ocean derived from VIIRS DNB images. Int. J. Remote Sens. 2018, 39, 8151-8181. [CrossRef]

14. Elvidge, C.; Zhizhin, M.; Baugh, K.; Hsu, F.C. Automatic boat identification system for VIIRS low light imaging data. Remote Sens. 2015, 7, 3020-3036. [CrossRef]

15. Geronimo, R.; Franklin, E.; Brainard, R.; Elvidge, C.; Santos, M.; Venegas, R.; Mora, C. Mapping fishing activities and suitable fishing grounds using nighttime satellite images and maximum entropy modelling. Remote Sens. 2018, 10, 1604. [CrossRef]

16. Elvidge, C.D.; Baugh, K.E.; Kihn, E.A.; Kroehl, H.W.; Davis, E.R.; Davis, C.W. Relation between satellite observed visible-near infrared emissions, population, economic activity and electric power consumption. Int. J. Remote Sens. 1997, 18, 1373-1379. [CrossRef]

17. Shi, K.; Yu, B.; Huang, Y.; Hu, Y.; Yin, B.; Chen, Z.; Wu, J. Evaluating the ability of NPP-VIIRS nighttime light data to estimate the gross domestic product and the electric power consumption of China at multiple scales: A comparison with DMSP-OLS data. Remote Sens. 2014, 6, 1705-1724. [CrossRef]

18. Wu, R.; Yang, D.; Dong, J.; Zhang, L.; Xia, F. Regional inequality in China based on NPP-VIIRS night-time light imagery. Remote Sens. 2018, 10, 240. [CrossRef]

19. Kyba, C.C.; Kuester, T.; De Miguel, A.S.; Baugh, K.; Jechow, A.; Hölker, F.; Guanter, L. Artificially lit surface of Earth at night increasing in radiance and extent. Sci. Adv. 2017, 3, e1701528. [CrossRef]

20. Levin, N.; Ali, S.; Crandall, D. Utilizing remote sensing and big data to quantify conflict intensity: The Arab Spring as a case study. Appl. Geogr. 2018, 94,1-17. [CrossRef]

21. Li, X.; Liu, S.; Jendryke, M.; Li, D.; Wu, C. Night-time light dynamics during the Iraqi civil war. Remote Sens. 2018, 10, 858. [CrossRef]

22. Zhao, X.; Yu, B.; Liu, Y.; Yao, S.; Lian, T.; Chen, L.; Wu, J. NPP-VIIRS DNB Daily Data in Natural Disaster Assessment: Evidence from Selected Case Studies. Remote Sens. 2018, 10, 1526. [CrossRef]

23. Li, K.; Chen, Y. A Genetic Algorithm-based urban cluster automatic threshold method by combining VIIRS DNB, NDVI, and NDBI to monitor urbanization. Remote Sens. 2018, 10, 277. [CrossRef]

24. Ma, W.; Li, P. An object similarity-based thresholding method for urban area mapping from visible infrared imaging radiometer suite day/night band (VIIRS/DNB) data. Remote Sens. 2018, 10, 263. [CrossRef]

25. Ma, T.; Yin, Z.; Zhou, A. Delineating spatial patterns in human settlements using VIIRS nighttime light data: A watershed-based partition approach. Remote Sens. 2018, 10, 465. [CrossRef]

26. Xue, X.; Yu, Z.; Zhu, S.; Zheng, Q.; Weston, M.; Wang, K.; Xu, H. Delineating urban boundaries using Landsat 8 multispectral data and VIIRS nighttime light data. Remote Sens. 2018, 10, 799. [CrossRef]

27. Du, M.; Wang, L.; Zou, S.; Shi, C. Modeling the census tract level housing vacancy rate with the Jilin1-03 satellite and other geospatial data. Remote Sens. 2018, 10, 1920. [CrossRef]

28. Liao, W.; Liu, X.; Wang, D.; Sheng, Y. The impact of energy consumption on the surface urban heat island in China's 32 major cities. Remote Sens. 2017, 9, 250. [CrossRef]

29. Chen, S.; Hu, D. Parameterizing anthropogenic heat flux with an energy-consumption inventory and multi-source remote sensing data. Remote Sens. 2017, 9, 1165. [CrossRef]

30. Davies, T.W.; Smyth, T. Why artificial light at night should be a focus for global change research in the 21st century. Glob. Chang. Biol. 2018, 24, 872-882. [CrossRef] [PubMed]

31. Elvidge, C.D.; Cinzano, P.; Pettit, D.R.; Arvesen, J.; Sutton, P.; Small, C.; Weeks, J. The Nightsat mission concept. Int. J. Remote Sens. 2007, 28, 2645-2670. [CrossRef]

32. Dobler, G.; Ghandehari, M.; Koonin, S.E.; Nazari, R.; Patrinos, A.; Sharma, M.S.; Wurtele, J.S. Dynamics of the urban lightscape. Inf. Syst. 2015, 54, 115-126. [CrossRef]

33. Hänel, A.; Posch, T.; Ribas, S.J.; Aubé, M.; Duriscoe, D.; Jechow, A.; Spoelstra, H. Measuring night sky brightness: Methods and challenges. J. Quant. Spectrosc. Radiat. Transf. 2018, 205, 278-290. [CrossRef]

34. Katz, Y.; Levin, N. Quantifying urban light pollution-A comparison between field measurements and EROS-B imagery. Remote Sens. Environ. 2016, 177, 65-77. [CrossRef]

35. Román, M.O.; Wang, Z.; Sun, Q.; Kalb, V.; Miller, S.D.; Molthan, A.; Seto, K.C. NASA's Black Marble nighttime lights product suite. Remote Sens. Environ. 2018, 210, 113-143. [CrossRef] 
36. Cao, X.; Hu, Y.; Zhu, X.; Shi, F.; Zhuo, L.; Chen, J. A simple self-adjusting model for correcting the blooming effects in DMSP-OLS nighttime light images. Remote Sens. Environ. 2019, 224, 401-411. [CrossRef]

37. Román, M.O.; Stokes, E.C. Holidays in lights: Tracking cultural patterns in demand for energy services. Earth's Future 2015, 3, 182-205. [CrossRef] [PubMed]

38. Levin, N.; Ali, S.; Crandall, D.; Kark, S. World Heritage in danger: Big data and remote sensing can help protect sites in conflict zones. Glob. Environ. Chang. 2019, 55, 97-104. [CrossRef]

39. Aubé, M.; Roby, J.; Kocifaj, M. Evaluating potential spectral impacts of various artificial lights on melatonin suppression, photosynthesis, and star visibility. PLoS ONE 2013, 8, e67798. [CrossRef] [PubMed]

40. Kyba, C.C.; Mohar, A.; Pintar, G.; Stare, J. Reducing the environmental footprint of church lighting: Matching facade shape and lowering luminance with the EcoSky LED. Int. J. Sustain. Light. 2018, 20, 1.

(C) 2019 by the authors. Licensee MDPI, Basel, Switzerland. This article is an open access article distributed under the terms and conditions of the Creative Commons Attribution (CC BY) license (http://creativecommons.org/licenses/by/4.0/). 